excursion may be arranged which will give an opportunity to explore the Ribble valley and to see something of the work which has recently been carried out at Whalley Abbey. Sectional excursions and visits will include the Metropolitan. Vickers Works at Manchester, Stonyhurst and Rossall, the freshwater biological station at Wray Castle, and the laboratories of Imperial Chemical Industries Ltd. at Blackley.
A four-days' excursion in the Furness district is being arranged in collaboration with the Yorkshire Geological Society immediately preceding the meeting, and a four-days' excursion to the Isle of Man after the meeting is under consideration.

The Mayor and Mayoress of Blackpool (Alderman Walter Newman, J.P., and Miss Newman) will hold a reception in the Winter Gardens on Thursday evening, September 10.

\title{
Scenic Geography at the Royal Academy
}

"W HAT will this year's Academy teach us about the scenery of the world?" was the question uppermost in my mind as I entered Burlington House. It was with particular satisfaction that I noted several instructive studies of the scenery of cities. The sky-line of the eity is bolder than any which Nature can produce, but in the strong light of day the scene is generally confusing in its multiplicity of form, and in colour often drab and dull. But Mr. C. R. W. Nevinson's two studies of London in twilight illustrate the advantages of civic scenery without its drawbacks. "Hail and Fairwell" (730) gives us a last view of the round arches of Waterloo Bridge with the harmonious curves of the dome of St. Paul's in the background, with the grey of twilight changed to a deep and tender shade of blue by the amber glow of the street lighting. In his second study, "Battersea Twilight" (727), the sky-line beyond a foreground of the Embankment and river is dominated not by a Cathedral but an industrial building, the Battersea Power House with its two great chimneys. There is a story that Whistler replied to a friend who complained of the prominence of factory chimneys, "Call them campaniles". It is to be hoped that in a future exhibition Mr. Nevinson's study may be followed by one taken from a nearer stand-point where the details of Sir Giles Gilbert Scott's design can be seen, particularly the fluting of the chimneys which so greatly enhances the columnar effect. This is the artistic touch that campaniles share but which the older factory chimneys lack. It is a hopeful sign of the times that the architect of Liverpool Cathedral has been entrusted with the design of this great industrial building. If the practice becomes general of obtaining the best architectural advice for factory building, the social benefit will be great, for if these huge erections were made beautiful the community would realise better the romance of industrial achievement.

Among the studies of purely natural scenery none has more poetic appeal than Mr. Julius Olsson's large painting of "Land's End and Long. ships Light" (151). Below the dark cliff a broad band of foaming surf is lit by the moon, which shines through a rift in the sombre clouds. Two studies of the Cornish coast (246 and 541), by Mr. Charles Simpson, remind us of the importance of taking steps to preserve this wild shore as $\mathbf{8}$ sanctuary of scenery. Mr. Borlase Smart's "Along our North-West Coast" (540) is one of the few studies of the shore viewed from the sea, which when the land is mountainous is one of the most attractive aspects of natural scenery. The recent extension of the programme of pleasure cruises, now much better organised than heretofore, would provido the sea painter with a travelling studio for such studies. Thus, passing west of Teneriffe on the outward and to the east on the homeward voyage of the Almanzora, I recently saw the whole circumference of the wonderful Peak from an advantageous distance with exquisite effects of clond and sky.

Of mountain scenery there is a fine example in Mr. Harry Van der Weyden's "From the Path to Castellar" (121), in which the nobility of height in associated with the solemnity of shadowed valleye where the sun's declining rays can no longer penetrate.

The quiet charm of the fields, woods and rural architecture of the English countryside is the welcome theme of many works. Mr. Oliver Hall's "Leckhampton Court from the Lawn" (22) pos. sesses in full measure the restful dignity charac. teristic of this artist's work. Mr. Alfred J. Munnings's "A Farm in Suffolk" (60) illustrates the advantageous setting which the small undulations of the Suffolk landscape provide for the picturesque old farm houses. The suave lines of the rolling chalk downs are the subject of pleasant watercolours by the Very Rev. W. Foxley Norris, "Chanctonbury Ring" (777) and by Mr. Charles H. Larkin, "The Downs, Poynings, Sussex" (956). 
In Mr. Karl Hagedorn's "Spanish Fishing Boats" (702) we have a study of the captivating curves of sailing craft which it is now so urgent to record.

Sir John Lavery's impressive portrait "Grey 0 wl" (553) is of special interest to the scientific world. This man, a Red Indian, by a self-denying life in the company of beavers, has carried our knowledge of an animal species to a point which it is only possible to attain when intellect is reinforced by loving-kindness.

\section{VAUGHAN CORNISH.}

Among the portraits of men of science are Catherine Dodgson's chalk drawing, "Sir Thomas Barlow, Bt., M.D., F.R.S." (1236) ; a white metal bust "Dr. Alexander Scott, F.R.S." (1518) by Sir W. Reynolds-Stephens ; a charcoal drawing of Sir Almroth Wright, K.B.E., C.B., M.D., F.R.S.
(1212) by Francis Dodd and also a bronze bust of Sir Almroth (1503) by Donald Gilbert; oil paintings of "Dr. J. Vargas Eyre, Ph.D., M.A." (375) by Algernon Talmage, and "A. E. Morgan, Esq., M.A., Principal and Vice-Chancellor of McGill University, Montreal, formerly Principal of University College, Hull" (409) by Frederick W. Elwell ; miniatures of "Emeritus Professor R. W. Reid, M.D., LL.D., F.R.C.S.”, emeritus regius professor of anatomy, University of Aberdeen (1055) by Isabella E. Reid, and "Bernard Dyer, Esq., D.Sc." (1133) by Inés Johnson; mezzotints of "Thomas Telford, after Sir Henry Raeburn, R.A." (1311) and "The Viscount Wakefield of Hythe, C.B.E." (1335) by H. Macbeth-Raeburn.

In addition, mention may be made of two architectural drawings by Charles Holden, "London University: Bird's-eye View from South-West" (1368) and "London University" (1451).

\section{Hofmann and his Influence on Chemistry in Great Britain}

IN his Hofmann Memorial Lecture, delivered at the Imperial College of Science and Technology on May 4, Prof. G. T. Morgan dealt with A. W. von Hofmann's career as chemist and teacher, and vividly recalled the extraordinary influence which he had on contemporary chemistry and chemical technology in Great Britain.

The main facts of Hofmann's life and work are well known through the original lectures delivered before the Chemical Society in 1893 by Lord Playfair, Sir Frederick Abel, Sir William Perkin and Prof. H. E. Armstrong. Hofmann came to England from Bonn in 1845 as a young man of twenty-seven, and spent the best years of his life in this country. Most chemical discoveries had until that time been the work of brilliant individuals, and it was left for Hofmann and for Graham to found the first schools for the training of chemical investigators. The times were peculiarly propitious for the new developments : Liebig's tour of the country in 1842 had awakened a general interest in chemistry, and, under the leadership of the Prince Consort, Sir James Clerk and Playfair, the Royal School of Mines and Royal College of Chemistry were founded. Hofmann became the first director of the latter, which rapidly developed as a centre for both instruction and original research. The early account books of the College show that chemistry became a popular and even fashionable study, owing no doubt to Hofmann's close associations with the Royal family. When he left England, twenty years later, to use Prof. Morgan's words, "Hofmann had established a school of research in organic chemistry such as had never existed before in this country."

Organic chemistry was then beginning the rapid development which was one of the main features of the science of the second half of the nineteenth century, and Hofmann was one of the first great chemists to specialise in this particular branch. His name is particularly associated with that of aniline, the compound which he described as his first love. In 1843, he investigated the "cyanol" of coal tar and suggested that this was identical with the bases "aniline" and "crystallin" prepared by the degradation of indigo and with the "benzidam" obtained by reducing nitrobenzene, a view which was afterwards shown to be correct. In later investigations he dealt with a wide range of derivatives of aniline, including the chloranilines and the phenyl carbamides. The early experiments were greatly hampered by scarcity of material; aniline was made from indigo and "the production of a few ounces was a proud achievement".

Hofmann was greatly attracted by Wurtz's contemporary discovery of monomethylamine and monoethylamine. This led him to investigate whether the remaining two hydrogen atoms attached to nitrogen in aniline and the alkylamines could be substituted by alkyl radicals without affecting the general nature of the bases. This led to the discovery of the alkyl anilines and of the quaternary ammonium compounds. Hofmann at once correctly interpreted the nature of these substances and their theoretical significance. Prof. 